\title{
A excitação no discurso televisivo dos Jogos Pan-americanos do Brasil: um estudo da transmissão da Rede Globo de Televisão
}

\author{
Guilherme Ferreira Santos* \\ Rafael Júnio Andrade Alves ${ }^{* *}$
}

\begin{abstract}
Resumo: Este artigo objetiva estudar a excitação contida no discurso televisivo durante a transmissão dos Jogos Panamericanos do Rio-2007 (PAN). Mais especificamente, estudar como o referido sentimento toma forma nas narrativas do discurso da Rede Globo de Televisão em um momento de transmissão do PAN: o discurso inicial da cerimônia de abertura. Para isso, recorreu-se ao pensamento de Elias e Dunning (1992) sobre o modo como a excitação é favorecida pelas atividades de lazer. Sendo um estudo de caso, foram utilizadas como técnicas para este estudo a documentação indireta (através de pesquisa documental e da pesquisa bibliográfica) e a Análise Crítica do Discurso.

Palavras-chave: Comunicação Persuasiva. Esportes. Televisão. Atividades de Lazer.
\end{abstract}

\section{INTRODUÇÃO}

O esporte é um fenômeno de grandes dimensões culturais e sociais que produz relações de diversos tipos que fazem parte do processo de formação humana de milhões de pessoas, sejam elas praticantes, sejam espectadoras. Em várias ocasiões, essas relações são veiculadas pelos meios de comunicação em massa. Segundo Raboy e Solervincens (2006), o termo "meios de comunicação":

[...] tomou relevância com o surgimento da comunicação a longa distância mediante a tecnologia - ou a telecomunicação. A telegrafia foi o primeiro meio de comunicação verdadeiramente moderno, depois rapi-

\footnotetext{
* Mestrando em Educação Física pela Universidade Federal do Espírito Santo. Pesquisador vinculado ao CESPCEO (Centro de Estudos em Sociologia das Práticas Corporais e Estudos Olímpicos). Espírito Santo, ES, Brasil. E-mail: jeffter@gmail.com

** Assistente de Coordenação do curso de Educação da UNICOR. Mestre em Extensão Rural pela Universidade Federal de Viçosa. Viçosa, MG, Brasil. E-mail: rafaefi@yahoo.com.br
} 
damente vieram a telefonia, o rádio, a televisão, a transmissão por cabo e satélite e, obviamente, a Internet. Todo este desenvolvimento aconteceu nos últimos 150 anos; a maior parte durante o último século e a Internet na década passada.

Assim, ao se analisar as recentes pesquisas que têm como objeto de estudo o esporte-sociedade, é notável o surgimento de investigações acerca do tema "Esporte e Mídia/Comunicação", as quais levam em consideração essa relevância atual dos meios de comunicação e suas funções enquanto "divulgadores" do esporte. No âmbito desse desenvolvimento surgem, com o objetivo de ampliar e aprofundar os estudos sobre o referido tema, Grupos de Trabalhos Temáticos em instituições de estudos no campo da Comunicação e da Educação Física, como, por exemplo, o Colégio Brasileiro de Ciências do Esporte (CBCE) e a Sociedade Brasileira de Estudos Interdisciplinares da Comunicação (INTERCOM).

Ficam evidentes que esses esboços, estudos e pesquisas acompanharam o desenvolvimento histórico de teorias da comunicação e da mídia. Hoje, o esporte é assistido, lido, sentido e ouvido através da mídia. Em muitos veículos, as seções mais procuradas são as esportivas.

As mídias nas quais acontecem as transmissões da mensagem esportiva são: a televisão, os jornais, a Internet, o rádio, as revistas etc. Nesse universo de transmissões, percebeu-se um campo fértil para pesquisas: o televisionamento dos Jogos Pan-americanos do Rio de Janeiro de 2007.

O interesse desta pesquisa foi, assim, estudar a excitação das emoções contida no discurso televisivo durante a transmissão dos Jogos. Mais especificamente, estudar como o referido sentimento toma forma nas narrativas do discurso da Rede Globo de Televisão em um momento de transmissão do PAN: o discurso inicial da cerimônia de abertura.

Os Jogos Pan-americanos representam um evento multiesportivo que ocorre de quatro em quatro anos, organizado pela Organização Desportiva Pan-Americana (ODEPA), a qual está subordinada ao Comitê Olímpico Internacional (COI). Durante o período de realização

Movimento, Porto Alegre, v. 16, n. 01, p. 227-244, janeiro/março de 2010. 
dos Jogos, todos os comitês olímpicos nacionais vinculados à ODEPA se confrontam em diversas modalidades esportivas, disputando qual "nação" ganha mais medalhas de ouro. É a catarse do esporte nas Américas. Os Jogos do Rio de Janeiro foram a décima quinta edição dos Jogos Pan-americanos e ocorreram de 12 a 29 de julho de 2007.

Para o presente artigo, tem-se como objetivo verificar qual a configuração, ou seja, como toma forma o discurso da excitação referente ao esporte e contido no televisionamento dos Jogos Pan-americanos do Rio de Janeiro pela Rede Globo de Televisão. Nesse sentido, intenta-se analisar o material coletado e perceber quais elementos extradiscursivos (contextos) estão relacionados ao discurso da excitação na transmissão dos Jogos pela Rede Globo no momento da cerimônia de abertura, assim como analisar as imagens e os sons e ver suas relações estratégicas com a excitação passada para os telespectadores.

\section{DeCisões METOdológicas}

Para Gil (2002, p. 41), toda e qualquer classificação se faz mediante algum critério e um dos critérios de classificação de pesquisas é com base em seus objetivos gerais. Em relação aos objetivos gerais existem três grandes grupos: as pesquisas exploratórias, as pesquisas descritivas e as pesquisas explicativas. A presente pesquisa se enquadra tanto no grupo das pesquisas descritivas quanto no das pesquisas exploratórias, pois objetiva descrever as características do fenômeno "comunicação do esporte tele-espetáculo" e também explorar o objeto de estudo, aumentar a familiaridade com o problema e aprimorar as ideias acerca do mesmo.

Com relação aos procedimentos técnicos, esta pesquisa se delineia como um estudo de caso, sem deixar de lado a pesquisa bibliográfica. Para Gil (1999, p. 72-73), um estudo de caso é

[...] caracterizado pelo estudo profundo e exaustivo de um ou de poucos objetos, de maneira a permitir o seu conhecimento amplo e detalhado, tarefa praticamente impossível mediante os outros tipos de delineamentos.

Movimento, Porto Alegre, v. 16, n. 01, p. 227-244, janeiro/março de 2010. 
Neste estudo, intenta-se aprofundar sobre o televisionamento pela Rede Globo dos Jogos Pan-americanos do Rio de Janeiro, mais especificamente, sobre um caso deste televisionamento, qual seja: o discurso inicial da cerimônia de abertura do PAN.

Com isso, serão utilizadas como técnicas para este estudo a documentação indireta através de pesquisa documental, a pesquisa bibliográfica e a Análise Crítica do Discurso.

A pesquisa documental se caracteriza por ter fontes de coleta de dados restrita a documentos, escritos ou não, constituindo o que se denomina de fontes primárias. Como exemplos dessas fontes têm-se: vídeos, gravações em fitas, filmes, documentos de arquivos públicos etc. (MARCONI; LAKATOS, 2007, p. 62-63). Nesta pesquisa, os dados foram coletados a partir de gravações em fitas (e posteriores gravações em DVD's) da transmissão do PAN na Rede Globo.

Já a pesquisa bibliográfica, ou de fontes secundárias, “abrange toda bibliografia já tornada pública em relação ao tema de estudo, desde publicações avulsas, boletins, jornais, revistas, livros etc."(MARCONI; LAKATOS 2007, p. 71).

A Análise Crítica do Discurso surge no final dos anos 80 e início dos anos 90 do século XX. Para Pedrosa (2005), ela é construída devido à identificação crítica de limites em outras teorias em Análise do Discurso. Dentro dessa teoria, o discurso constitui simultaneamente "três dimensões que se interrelacionam: texto, interação (prática discursiva) e contexto (prática social)" (FAIRCLOUGH, 1992 apud GOMES, 2007, p. 16). Chama-se esta constituição de quadro tridimensional de Fairclough.

O dispositivo de análise é, então, construído em função de três dimensões múltiplas que se interrelacionam: a análise textual, essa primeira dimensão é baseada na "tradição de análise textual e linguística. É a dimensão que cuida da análise linguística. A análise textual deve ser feita conjuntamente com as outras dimensões." (PEDROSA, 2005); a análise discursiva, sobre a prática discursiva (produção, distribuição e consumo); a análise social, que objetiva especificar "a natureza da prática social da qual a prática discursiva é uma parte, constituindo a

Movimento, Porto Alegre, v. 16, n. 01, p. 227-244, janeiro/março de 2010. 
base para explicar por que a prática discursiva é como é [...]" (FAIRCLOUGH, 2001, p. 289 apud PEDROSA, 2005).

Após essa explanação, abre-se aqui uma categoria discursiva: a "excitação das emoções”, discutida por Elias e Dunning (1992).

\section{A SOCIEDADE MODERNA E O FENÔMENO ESPORTIVO}

Nas sociedades ditas tradicionais, as práticas corpóreas, assim como todas as atividades sociais, caracterizavam-se fortemente pela influência da religião. A religião era o "primeiro discurso", o centro que totalizava o sentido das práticas socioculturais e as dotava de significação. Com o advento da modernidade, o esporte, no seu processo de constituição/construção é influenciado pelas transformações socioculturais e incorpora uma série de características da sociedade industrial moderna (BRACHT, 2003a, p. 85).

Para Bracht (2003b, p. 13-14), o esporte moderno é resultado da esportivização de elementos da cultura corporal de movimento das classes populares e da nobreza inglesas. Tal processo, segundo o autor, inicia-se em meados do século XVIII e se intensifica no final do século XIX e início do século XX.

Dunning (1979, p. 42 apud BRACHT, 2003b, p. 14) diz que o declínio dos jogos populares começa em torno de 1800. Esses jogos foram, pouco a pouco, entrando em desuso pois os processos de urbanização e industrialização trouxeram consigo novos padrões e condições de vida que não tinham mais compatibilidade com tais jogos. Desse modo, as funções iniciais dos jogos tradicionais, as quais eram relacionadas às festas (da colheita, religiosas etc.), foram sendo esvaziadas e a forma tradicional desses jogos foi sendo considerada "ameaça à propriedade e à ordem pública." (BRACHT, 2003b, p. 14). Esses jogos, porém, sobrevivem nas Public Schools inglesas, local onde não eram vistos como ameaça: "Vai ser nas escolas públicas que aqueles jogos (o caso clássico é o futebol) vão ser regulamentados e aos poucos assumir as características (formas) do esporte moderno." (BRACHT, 2003b, p. 14). O autor ainda afirma que "esse fenômeno esportivo [...] tomou como de assalto o mundo da cultura corporal de

Movimento, Porto Alegre, v. 16, n. 01, p. 227-244, janeiro/março de 2010. 
movimento, tornando-se sua expressão hegemônica, ou seja, a cultura corporal de movimento esportivizou-se."

Para Helal (1990, p. 44), o esporte moderno possui algumas características que o diferenciam do esporte de outras épocas. Uma dessas características que se destaca é a racionalização. Helal diz que racionalizar consiste em se conformar às leis da razão, o que representa para o mesmo "um processo pelo qual se faz entrarem no campo da razão realidades que, anteriormente, estavam fora dela." (HELAL, 1990, p. 44). O autor coloca ainda algumas peculiaridades da racionalização. Vê-se aqui uma delas, a qual se relaciona bastante com os objetivos desse trabalho: a quantificação.

A quantificação é característica visível e explícita no esporte moderno. Observa-se a tendência a transformar qualquer atividade atlética/esportiva em algo mensurável, quantificável. Nota-se que na Grécia antiga, por exemplo, o esporte não era quantificado, pois importava quem vencia (quem chegava na frente, quem lançava mais longe etc.) e não quantos metros fez, qual velocidade, qual a média da velocidade nos últimos anos, qual sua correlação com o desenvolvimento humano, qual tempo se alcançou etc. Essa quantificação é "respeitada" pelos praticantes e espectadores esportivos, sendo que nas discussões sobre qual é o melhor time ou qual é o melhor atleta ela é uma das argumentações principais. Helal diz que "essa mania pela quantificação a todo custo está intimamente ligada à ideia de progresso, que teoriza em cima de um conceito linear de que cada melhoria pode ser ainda melhorada infinitamente."' (HELAL, 1990, p. 49).

\section{A EXCITAÇÃO NO CAMPPO ESPORTIVO}

Para compreender o conceito de excitação aqui utilizado é necessário recorrer à teoria do processo civilizador de Norbert Elias. Esse autor é um marco para a sociologia de maneira geral. Ele representa uma das figuras centrais da formação do ramo sociológico conhecido como sociologia configuracional. Nesta vertente, desenvolveu a refe-

${ }^{1}$ Noção de recorde.

Movimento, Porto Alegre, v. 16, n. 01, p. 227-244, janeiro/março de 2010. 
rida teoria, na qual os indivíduos não poderiam ser encarados como opostos à sociedade (indivíduos x sociedade). Assim:

[...] a individualização não é um estado, mas uma relação construída a partir de uma crescente interação e dependência - uma configuração - ou seja, estabelecem-se interrelações que permitem às relações humanas serem balizadas no processo civilizador, não como campo de liberdade ou de pura dominação, mas como um elemento de libertação. (LUCENA, 2002 , p. 121, grifos do autor).

Grosso modo, define-se processo civilizador como:

[...] um processo necessariamente não planejado e imprevisível, em especial no que diz respeito às alterações de longo prazo que tem ocorrido nas figurações humanas. [...] O ponto central, no qual se apoia a teoria do processo de civilização, é a existência deste processo "cego" (não planejado), e empiricamente evidente. Trata-se do processo de "cortenização" e/ou parlamentarização dos guerreiros medievais; isto equivale a dizer, em termos práticos: a violência imbricada no cotidiano dos guerreiros cede lugar ao debate e ao refinamento das atitudes dos cortesãos. A solução dos conflitos e o controle da violência passam a ser encaminhados de formas distintivas em relação ao uso imediato e explícito da força/violência. (GEBARA, 2000, p. 35-36).

A partir dessa teoria (do processo civilizador), Norbert Elias e seu aluno Eric Dunning partiram para um estudo ou um conjunto de estudos do esporte (e do lazer, de modo geral) dentro desse momento histórico de mudança de comportamentos, escrevendo "A busca da Excitação" (1992), um livro que reúne textos de ambos os autores sobre o esporte moderno e suas "contribuições" no processo civilizador.

Elias e Dunning colocam que nas sociedades industriais mais avançadas, algumas das ocorrências mais básicas de crise da humanidade, como a fome, as inundações, as epidemias e a violência realizadas por pessoas de alta condição social ou por estranhos, foram submetidas, de maneira progressiva, a um rigoroso controle. O mesmo ocorreu com as paixões, explosões incontroladas ou incontroláveis de forte excitação coletiva que se tornaram cada vez menos frequentes. Os citados auto-

Movimento, Porto Alegre, v. 16, n. 01, p. 227-244, janeiro/março de 2010. 
res, então, afirmam que "os indivíduos que agem de forma bastante excitada, sujeitam-se a serem conduzidos a um hospital ou à prisão." (ELIAS; DUNNING, 1992, p. 101-102).

Para Elias e Dunning (1992, p. 45), no desenrolar do século XX, as competições físicas, em sua forma de regulamentação conhecida como esporte, chegaram a assumir-se como representação simbólica da forma não violenta e não militar de conflito entre Estados, sendo o esporte (desde sua gênese imbricada ao processo civilizador) uma competição entre empenhos dos seres humanos que exclui, na medida do possível, ações de violência que podem ter como consequências agressões sérias nos competidores.

Destarte, o autor, posteriormente, diz que o modo como se animam os sentimentos e como a excitação é favorecida pelas atividades de lazer é dinamizado, habitualmente, por meio da criação de tensões que estariam relacionadas, segundo ele, com um perigo imaginário, medo ou prazer mimético, sendo que há a produção de tristeza e alegria juntamente com uma resolução destes elementos no quadro dos divertimentos. Em outras palavras:

Deste modo, os sentimentos dinamizados numa si-
tuação imaginária de uma actividade humana de lazer
têm afinidades com os que são desencadeados em
situações reais da vida - é isso que a expressão "mimé-
tica" indica - mas, o último está associado aos riscos
e perigos sem fim da frágil vida humana, enquanto o
primeiro, sustenta, momentaneamente, o fardo de
riscos e de ameaças, grandes e pequenas, que rodeia a
existência humana. (ELIAS; DUNNING, 1992,p. 71).

Os Jogos Olímpicos, conforme Elias e Dunning, são um exemplo nítido de certa tentativa de "apaziguar" essas tensões "torpes", fazendo com que, no campo dos confrontos, não estejam apenas dois países, mas todo o globo (ELIAS; DUNNING, 1992, p. 72). Quando isso acontece, certos aspectos do esporte mudam e o deixam, de acordo com estes autores, com um caráter diferente daquele que se revela como forma de lazer. Contudo, com certos limites, Elias e Dunning apontam que há um tipo de "realização desportiva" que conserva o caráter de ocupação de lazer: o esporte espetáculo. Sob esta perspectiva:

Movimento, Porto Alegre, v. 16, n. 01, p. 227-244, janeiro/março de 2010. 
[...] o desporto pode resultar numa agradável excitação mimética, que é susceptível de contrabalançar as tensões, normalmente desagradáveis, das pressões derivadas do stress inerente às sociedades, proporcionado uma forma de restauração de energias. (ELIAS, DUNNING, 1992, p. 72-73, grifos nossos).

Aí se observa certo paradoxo interessante em Elias e Dunning. Não é um paradoxo que exponha falta de lógica em suas ideias. Ao contrário, percebe-se que eles focalizam algo muito importante para o entendimento da gênese e do desenvolvimento do esporte moderno dentro do processo civilizador: o "descontrole controlado":

\begin{abstract}
Muitas dessas ocupações de lazer, entre as quais o desporto nas suas formas de prática ou de espectáculo, são então consideradas como meios de produzir um descontrolo de emoções agradável e controlado. Com frequência, elas oferecem (embora nem sempre) tensões miméticas agradáveis que conduzem a uma excitação crescente e a um clímax de sentimentos de êxtase, com a ajuda dos quais a tensão pode ser resolvida com facilidade, como no caso de a sua equipa vencer uma prova desportiva. (ELIAS, DUNNING, p. 73, grifo nosso).
\end{abstract}

Esse paradoxo é possível por causa das características do processo civilizador e de suas consequências na mudança do comportamento das pessoas. Há uma repressão das tensões com o processo civilizador. O que era considerado civilizado pelas "cortes" europeias na Idade Média era muito diferente das ações "bárbaras", das classes mais baixas. Assim, historicamente, o comportamento das pessoas foi mudando conforme os padrões de civilidade (tanto na Alemanha quanto na França e na Inglaterra). As emoções, então, eram contidas e controladas. Não se podia mais comer da maneira como se comia ou andar ou agir em público como se agia. O esporte moderno, então, surge na Inglaterra dentro desse contexto de controle e ele tem seus regulamentos (o que o deixa também, até certo ponto, controlado). Porém, ali, pode-se agir de maneira que não se poderia fazer caso o momento fosse outro. A partir disso é que se pode falar em um "descontrole controlado".

Movimento, Porto Alegre, v. 16, n. 01, p. 227-244, janeiro/março de 2010. 
Enfim, destaca-se que para Mauro Betti (2005), Elias e Dunning não queriam dizer que apenas o "praticar esportes" seria a satisfação da experimentação de fortes emoções, pois o "assistir esportes" também o é. Assim, ao assistir o esporte pela TV (esporte tele-espetáculo) o telespectador também busca a excitação.

\section{Os JOGOS DO RIO DE JANEIRO E AS EXCITAÇÕES EM CURSO}

Para esta pesquisa seria inviável analisar todo o material relacionado aos Jogos. Então, escolheu-se um momento dos Jogos que tivesse bastante identificação e relação com a problemática proposta: a cerimônia de abertura dos Jogos que ocorreu no dia 13 de julho de 2007, ao cair da tarde e início da noite, no Estádio Jornalista Mário Filho, mais conhecido como "Maracanã". Foi feita uma transcrição do discurso inicial desta cerimônia, o qual constitui o corpus principal desta análise.

Para a transmissão da cerimônia de abertura, a Rede Globo colocou seu principal locutor esportivo, Galvão Bueno (GB), acompanhado de repórteres de renome na conjuntura atual da comunicação brasileira: Marcos Uchôa, João Pedro Paes Leme e Fátima Bernardes.

Nesse discurso inicial, Galvão Bueno cumprimenta os telespectadores sucintamente e começa sua fala de maneira um pouco diferente: ao invés de começar a narrar os fatos e contextualizar o público sobre o que está acontecendo no local, ele pronuncia um discurso sobre a diferença entre os povos das Américas e como o esporte atua sobre essas diferenças. Ele coloca o esporte como fator de união entre os povos das Américas. A sua fala, por tal vez, vem de um texto escrito. Várias pistas levam a compreender isso, como, por exemplo, não há resquícios de hesitação na fala, a estruturação do texto é de um texto escrito e as pausas são programadas e bem posicionadas. Já neste discurso, observa-se a excitação das emoções. Quando Galvão Bueno fala sobre a diversidade, usa um argumento emotivo: "Diversidade: a palavra que nos separa e nos une ao mesmo tempo. Somos pobres e ricos. Falamos línguas diferentes. Mas é exatamente pelo que nos distingue que reconhecemos fraquezas e virtudes".

Reconhecer "fraquezas" e "virtudes" é um ato, então, fora do cotidiano. É possível fazer tal reconhecimento com a percepção da

Movimento, Porto Alegre, v. 16, n. 01, p. 227-244, janeiro/março de 2010. 
lógica dos Jogos Pan-americanos (união dos povos) e da lógica do esporte em si. Isso materializar-se-á nas solenidades que estão para acontecer na cerimônia de abertura dos Jogos. Portanto, torna-se emocionante ver ao vivo essa cerimônia. É transmitida a impressão, para o telespectador, de que ele tem a oportunidade de ver essa materialização. E tudo isso acontece com a celebração do esporte através da cerimônia, a qual tipifica essa materialização, quando Galvão Bueno diz: "Hoje, as Américas se encontram no Rio de Janeiro. Na celebração do esporte, um convite à tolerância e à paz."

O locutor, então, tenta elevar ao máximo essa excitação no discurso inicial falando sobre os atletas, os quais, segundo ele, vivem em um dualismo constante: são astros, seres especiais que buscam o Olimpo ${ }^{2}$ grego mas, ao mesmo tempo, são homens normais, que sentem dor, que choram:

GB: Teremos diante de nós grandes astros do esporte mundial. Mediremos os recordes em centésimos e em centímetros. Olharemos com admiração esses seres especiais que buscam o Olimpo grego sem que as fronteiras das Américas diminuam este sonho. Ir ao mais alto, mais longe, ser o mais forte, como se sublinhassem o Ideal Olímpico em cada gesto e escrevessem em novas páginas do heroísmo com os seus próprios corpos. Mas atletas não são super-heróis encarnados. Nesse mundo mágico de campeões, quase mitos, basta a primeira lágrima pra se revelar a parte humana de quem está ali, ou mesmo um riso ou um grito incontido que venha da alma. O esporte é um misto de intuição e disciplina. Eno momento em que se revela humano, o ídolo apaixona o fã.

O Ideal Olímpico reforça a ideia de superação que se deve ter no esporte e na vida. Esta é a apropriação social que Galvão Bueno faz do esporte, ou seja, é o sentido social que ele atribui ao esporte. Para se entender como ele chega a essa conclusão, é necessário compreender sua prática social, ou seja, seu

[...] modo de ação historicamente situado, que tanto é constituído socialmente como tambémé constitutivo

${ }^{2}$ Olimpo: lugar onde habitam as divindades greco-latinas (HOUAISS; VILLAR; FRANCO, 2001).

Movimento, Porto Alegre, v. 16, n. 01, p. 227-244, janeiro/março de 2010. 
de identidades sociais, relações sociais e sistemas de conhecimento e crença. (FAIRCLOUGH, 1989, apud RESENDE; RAMALHO, 2006, p. 26-27).

Então qual seria o modo de ação, historicamente situado, do locutor da Globo enquanto profissional da comunicação? Sabe-se que o contexto de criação da Rede Globo de Televisão advém de uma perspectiva mercadológica de lucro. ${ }^{3}$

O locutor, então, está inserido em uma rede de relações sociais reveladora: trabalha para a maior empresa de televisão do Brasil, sendo um país de terceiro mundo constituído de uma economia crescente, porém com uma das piores distribuições de renda do mundo - 75\% da renda total vão para 10\% da população (CAMACHO, 2008); a educação é deficitária e o locutor tem consciência de que é formador de opinião; há uma apropriação do esporte em seu contexto social que parece ser dominante no Brasil (o esporte como fator de ascensão social). Diante disso, percebe-se que Galvão Bueno é influenciado por essa apropriação social e também influencia seus telespectadores. Ou seja, seu discurso é constituído dessa apropriação do "esporte enquanto fator de ascensão social" e é também constitutivo dela, forma opiniões para futuras apropriações sociais com este mesmo sentido.

Essa ideia é reforçada pela noção de "idolatria" que o locutor passa aos seus consumidores de informação: "E no momento em que se revela humano, o ídolo apaixona o fâ". A "paixão" pelo ídolo é componente "excitador" da estratégia televisiva do locutor. Assim, na medida em que o fã percebe seu ídolo como humano (sob condições igualitárias), ele (o fã) também se vê com chances de, por meio do esporte, ascender socialmente.

Após o exposto, pode-se observar uma categoria de análise relacionada ao significado identificacional e ao estilo do texto: a metáfora. Quando o locutor a usa em "escrever novas páginas do heroísmo com seus próprios corpos", ele deixa transparecer uma excitação marcante: o uso do corpo (de maneira regrada) no esporte como libertação acional. O esporte, então, outorga seus praticantes e espectadores a realizarem uma ação socialmente demarcada (fazer parte da história da socie-

${ }^{3}$ Conferir o documentário britânico "BRAZIL: Beyond Citizen Kane" de Simon Hartog.

Movimento, Porto Alegre, v. 16, n. 01, p. 227-244, janeiro/março de 2010. 
dade) através de sua prática ou do próprio fato de estar ali, assistindo àquele evento histórico. O "mundo mágico", sobre o qual fala Galvão Bueno, remete ao mimetismo presente na obra de Elias e Dunning.

Outro enunciado que chama bastante atenção neste pronunciamento de Galvão Bueno é: "É a vibração que nos contagia, a emoção que nos inspira, a vontade que nos energiza."A relação entre os três verbos principais deste enunciado e seus respectivos sujeitos e predicados (vibração nos contagia; emoção nos inspira; vontade nos energiza) transparecem a excitação televisiva. Galvão Bueno pronuncia claramente, ante a sua prática social já discutida aqui, a excitação do teleespetáculo esportivo, afinal, "energizar" significa, na conjuntura da sociedade moderna, excitar, sair da esfera do "civilizado" por um instante - de maneira permissiva - afinal, está-se falando sobre o esporte.

Posteriormente, Galvão Bueno caracteriza o esporte exatamente como Pires (2002, p. 90) o define: "tele-espetáculo", pois possui uma universalização da linguagem:

Nos próximos dezesseis dias, quarenta e duas nações pan-americanas falarão quatro idiomas distintos, mas levarão uma mensagem que dispensa traduções. O esporte e a música são línguas universais: Falam sem dizer, e dizem, mesmo assim, algo tão encantador que não há quem fique indiferente.

No seguinte enunciado, o locutor da Globo dá importância ao "testemunho" dessa excitação:

\begin{abstract}
Hoje é um dia especial para o Rio, para o Brasil, para as Américas. Cinco mil e quinhentos atletas começam a sonhar. E nós seremos testemunhas deste devaneio. Uma espécie de sonho coletivo, em que os desejos se misturam como se espectador e espetáculo formassem a alma do artista. As arenas esportivas como redomas de um mundo em que se busca apenas o melhor de si ensinam dezenas de lições. Nelas é possível competir com respeito, aceitar a derrota dignamente, obedecer às regras do jogo.
\end{abstract}

Esse testemunho é importante, pois, segundo Galvão Bueno, acontecem coisas no esporte que possuem um juízo de valor muito forte e emotivo na conjuntura social atual: o competir com respeito, o aceitar

Movimento, Porto Alegre, v. 16, n. 01, p. 227-244, janeiro/março de 2010. 
a derrota e o obedecer às regras. Percebe-se que esses são preceitos que estão vinculados ao processo tecnocrático da sociedade industrial neoliberal.

Outro elemento constitutivo do discurso refere-se ao componente da fantasia. O locutor coloca a realização dos Jogos, aqui no Brasil, no mundo dos sonhos, sobre o qual discorre Marcondes Filho (1988), relacionando esse "mundo da fantasia" com a TV. Os atletas e os espectadores, que tanto desejavam a ocorrência desses Jogos no Brasil, têm agora a satisfação desse desejo como elemento excitante.

Galvão Bueno fecha este discurso falando que as medidas do mundo do esporte, especificamente, do mundo dos Jogos Pan-americanos, são a emoção, a vontade e o estímulo:

\begin{abstract}
GB: [...] os recordes continuarão medidos em centésimos ou centímetros. Mas a grande transformação que o esporte permite não se mede com escala de tempo ou de espaço. A grande transformação virá dentro de cada um que se motivar pelos Ideais Olímpicos. A partir de hoje, o estímulo, a vontade e a emoção passam a ser as medidas deste mundo de personagens que inspiram e transformam. Celebrar a humanidade é uma forma de sonhar coletivamente e perpetuar a esperança.
\end{abstract}

Isso se traduz em excitação na medida em que as vontades, as emoções e os estímulos são provocados em situações de lazer dos telespectadores, diferenciando seu momento de trabalho. Mas não é apenas isso que caracteriza uma forte excitação. A ansiedade pelos Jogos (que já estavam sendo divulgados há muito tempo) faz com que esta situação seja de uma excitação maior, pois o locutor argumenta que a "celebração da humanidade" a partir desse "estímulo", dessa "vontade" e dessa "emoção" traz um sentimento diferente do cotidiano dos telespectadores (afinal, a última vez que um discurso desse pôde ser pronunciado em solo brasileiro foi em 1963, quando os Jogos foram realizados em São Paulo): a esperança. Ele não fala em quê, deixando isso aberto aos desejos de cada um.

Movimento, Porto Alegre, v. 16, n. 01, p. 227-244, janeiro/março de 2010. 


\section{CONSIDERAÇÕES FINAIS}

A análise do corpus neste estudo aponta que o discurso da Rede Globo de Televisão durante esta cerimônia produziu uma excitação das emoções no telespectador. É possível concluir, assim, que um dos aspectos discursivos ao qual a excitação está relacionada é seu uso enquanto prática social dos falantes da Rede Globo.

A análise aponta também para uma característica da linguagem na TV discutida por Cabral (2001, p. 44-45). Ele, discorrendo sobre o controle (ou manipulação) da TV, afirma:

[...] é cada vez mais difícil - em virtude da explosão demográfica e de todos os outros fatores ligados à concentração urbana - o controle direto das ações e dos comportamentos. Assim, o controle tem de ser assumido individualmente pelos próprios controlados. É o controlado quem controla [...] - e nisto reside a astúcia do Poder.

Percebe-se essa ideia em alguns momentos do discurso analisado, onde, levando-se em consideração o contexto sócio-histórico da produção da comunicação, notaram-se ideologias (implícitas e explícitas) em prol de um futuro controle do próprio telespectador. Vê-se também que esse controle (realizado pelo próprio controlado), relaciona-se de maneira interessante com o processo de "descontrole controlado" ao qual se referem Elias e Dunning e já citado nesse trabalho.

Movimento, Porto Alegre, v. 16, n. 01, p. 227-244, janeiro/março de 2010. 


\begin{abstract}
The excitement in television discourse of Pan American Games of Brazil: a study of the channel Globo's transmission

Abstract: This article aims to study the excitement in the television discourse during the transmission of the Pan American Games in Rio-2007. More specifically, how that feeling takes shape in the narratives of the discourse of Rede Globo in a moment of transmission of the Games: the opening speech of the opening ceremony. For this, we appealed to the thought of Elias e Dunning (1992), about how the excitement is favored by leisure activities. Since this is a case study, we used as technique for this study the indirect documentation (through desk research and bibliographic research) and Critical Analysis of Discourse.

Keywords: Persuasive Communication. Sports. Television. Leisure activities.
\end{abstract}

\begin{tabular}{|l|}
\hline La excitación en el discurso de televisión de los \\
Juegos Panamericanos en Brasil: un estudio de \\
la transmisión de la Rede Globo de Televisión \\
Resumen : Este artículo tiene como objetivo estudiar \\
la excitación en el discurso de la televisión durante la \\
transmisión de los Juegos Panamericanos en Río-2007. \\
Más concretamente, cómo ese sentimiento toma forma \\
en descripciones del discurso de Rede Globo en un \\
momento de la transmisión del PAN: el discurso inicial \\
de la ceremonia de apertura. Para esto, hizo un llama- \\
miento a la reflexión de Elías (1992), acerca de cómo \\
la excitación es favorecida por las actividades de ocio. \\
Como estudio de caso, se utiliza como técnica la docu- \\
mentación indirecta (a través de investigación docu- \\
mental y búsqueda bibliográfica) y Análisis Crítico del \\
Discurso. \\
Palabras clave: Comunicación Persuasiva. Deportes. \\
Televisión. Actividades recreativas. \\
\hline
\end{tabular}

\title{
REFERÊNCIAS
}

BETTI, Mauro. Esporte, entretenimento e mídias: implicações para uma política de esporte e lazer. Impulso, Piracicaba, v. 16, n. 39, p. 83-89, 2005. Disponível em: <http://www.unimep.br/phpg/editora/revistaspdf/imp39art06.pdf>. Acesso em: 13 mar. 2008.

Movimento, Porto Alegre, v. 16, n. 01, p. 227-244, janeiro/março de 2010. 
BRACHT, Valter. Educação física \& ciência: cenas de um casamento (in)feliz. 2. ed. ljuí: Ed. da UNIJUÍ, 2003a. 2003b.

Sociologia crítica do esporte: uma introdução. 2. ed. rev. ljuí: Ed. da UNIJUÍ,

CABRAL, Muniz Sodré. de Aaraújo. O monopólio da fala: função e linguagem da televisão no Brasil. 7. ed. Petrópolis: Vozes, 2001.

CAMACHO, Karen. 10\% mais ricos no Brasil detêm $75 \%$ da riqueza, diz Ipea. Folha Online, São Paulo, 15 maio 2008, Dinheiro. Disponível em: <http://www1.folha.uol. com.br/folha/dinheiro/ult91u402034.shtml>. Acesso em: 22 maio 2008.

ELIAS, Norbert; DUNNING, Eric. (Org.). A busca da excitação. Tradução Maria Manuela Almeida e Silva. Lisboa: Difel, 1992.

GEBARA, Ademir. Norbert Elias e a teoria do processo civilizador: contribuição para a análise e a pesquisa no campo do lazer. In: BRUHNS, H. T. (Org.). Temas sobre lazer. Campinas: Autores Associados, 2000. p. 33-46.

GIL, Antônio Carlos. Como elaborar projetos de pesquisa. 4. ed. São Paulo: Atlas, 2002.

Métodos e técnicas de pesquisa social. 5. ed. São Paulo: Atlas, 1999.

GOMES, Maria Carmen Aires. Considerações sobre os estudos discursivos críticos: o projeto social discursivo de Norman Fairclough. In: GOMES, M. C.; MELO, M. S. de S.; CATALDI, C. Gênero discursivo, mídia e identidade. Viçosa: Ed. da UFV, 2007. p. 13-31.

HELAL, Ronaldo. O que é sociologia do esporte. São Paulo: Brasiliense. 1990.

HOUAISS, Antônio; VILLAR, Mauro de Salles; FRANCO, Francisco Manoel de Mello. (Ed.). Dicionário eletrônico Houaiss da língua portuguesa. Rio de Janeiro: Objetiva, 2001. 1 CD-ROM.

LUCENA, Ricardo de Figueiredo. Elias: individualização e mimesis no esporte. In: PRONI, Marcelo Weishaupt; LUCENA, Ricardo de Figueiredo. (Org.). Esporte: história e sociedade. Campinas: Autores Associados, 2002. p. 113-138.

MARCONDES FILHO, Ciro. Televisão: a vida pelo vídeo. São Paulo: Moderna, 1988.

MARCONI, Marina de Andrade; LAKATOS, Eva Maria. Técnicas de pesquisa: planejamento e execução de pesquisas, amostragens e técnicas de pesquisas, elaboração, análise e interpretação de dados. 6. ed. rev. ampl. São Paulo: Atlas, 2007.

PEDROSA, Cleide Emília Faye. Análise Crítica do Discurso: uma proposta para a análise critica da linguagem. Cadernos do CNLF, Rio de Janeiro, v. 9, n. 3, jul. 2005. Disponível em: <http://www.filologia.org.br/ixcnlf/3/04.htm>. Acesso em: 11 mar. 2008.

Movimento, Porto Alegre, v. 16, n. 01, p. 227-244, janeiro/março de 2010. 
244 Artigor Originais Guilherme F. Santos e Rafael J. A. Alves

PIRES, Giovani de Lorenzi. Educação física e o discurso midiático: abordagem crítico-emancipatória. ljuí: Ed. da UNIJUÍ, 2002.

RABOY, Marc; SOLERVINCENS, Marcelo. Meios de comunicação. [S.I.: s.n.], 2006. Disponível em: <www.vecam.org/article684.html>. Acesso em: 08 maio 2007.

RESENDE, Viviane de Melo; RAMALHO, Viviane. Análise de discurso crítica. São Paulo: Contexto, 2006.

Recebido em: 26/01/2009

Aprovado em: 02/08/2009

Movimento, Porto Alegre, v. 16, n. 01, p. 227-244, janeiro/março de 2010. 